\title{
6 \\ Approaches to Help in Organizations
}

The river Akerselva runs through Oslo, from north to south, forming a boundary between the east and the west parts of the city. On hot summer days, the river is a popular place to cool down with a bath or go for a swim. People of all ages can normally enter the river and enjoy the water, but sometimes the current is too strong, and the city council advises people to stay on the shore. There are always a few people who nevertheless decide to enter the river. They are usually strong, athletic types, who are able to look after themselves, and have the muscles and energy to go in and out of the strong current.

A few years ago, there was a noteworthy incident at one of the most popular bathing spots along the river. It was one of those days with a strong current, where most people lay on the shore instead of stepping into the river. A young man was standing in the middle of the river, at the top of a small waterfall. It is usually a comfortable place to stand, facing away from the waterfall, with water gliding at and past you at breast height, but on this day, the stream was faster and more forceful than usual.

From time to time, the man would move towards the shore, and then walk backwards to the spot by the waterfall again. He kept standing 
there, and people were starting to leave the bathing place for the day. Now it started to look odd that the young man was still standing out in the river, with water rushing at and past him. Somebody shouted out to him: Do you need help? He responded very quickly with a muted confirmation. Yes, he really needed help. This young, athletic man was stuck in the river with its strong current, and had been so for some time. The moves he had made towards the shore were actually failed attempts to get out of the river. Now he was cold and lacked energy to move. A group of people had to hold hands and make a line out into the river, to drag him out of the water.

This chapter explores how initiatives to seek, offer, and provide help is a central ingredient in coping with fallibility at work. First, it revisits two of the psychological phenomena discussed in earlier chapters-the bystander effect and the confirmation fallacy-to consider how they can contribute to an understanding why people are hesitant to seek and offer help. Second, it focuses on the perception of social cost as an explanation of why people might refrain from seeking help in critical situations at work. The starting point for that discussion is two examples from healthcare, one real and one fictitious, in which inexperienced professionals attempt to do things on their own, without help or support from colleagues. Third, it considers how systems of holding back can make people mute and passive in situations where they either need or are in a position to offer help. One person can withhold help to another, thinking that the other would probably not have gone out of his or her way to help if the roles had been reversed. When both have this assumption about the other, a system of holding back is in place, and it inhibits helping behavior.

Helping behavior among colleagues increase the likelihood that work units and organizations succeed (Grant, 2014; Grant \& Patil, 2012; Kahn \& Katz, 1966). Research on helping at work frames it as "prosocial, promotive and cooperative behaviors intended to benefit others" (Grant \& Patil, 2012, p. 547). It includes assisting colleagues with workrelated operations (Anderson \& Williams, 1996), supporting colleagues who face personal problems (Kahn, 1998), and expressing compassion and care towards colleagues. Helping behaviors are fundamental building blocks of organizing, the process through which individual employees 
coordinate their efforts to achieve collective goals (Grant \& Patil, 2012; Weick, 1979). They belong to the altruism dimension of what is called organizational citizen behavior, "individual behavior that is discretionary, not directly or explicitly recognized by the formal reward system, and in the aggregate promotes the efficient and effective functioning of the organization" (Organ, Podsakoff, \& MacKenzie, 2006). The contribution of the current chapter is to tie helping behavior to the specific challenge of coping with fallibility at work.

\section{Beyond the Crowd}

The young man who could not get out of the waterfall by himself only got help when the crowd at the shore had diminished to only a handful of people. He had not been in constant need of help from the moment he stepped into the river. His capacity to handle the situation on his own gradually deteriorated with each effort to get out of the river by himself. Even if his condition got gradually worse, it seems likely that he to some degree was a victim of the bystander effect. When many people were present, none took any initiative to ask about his condition. As people started to go home from the bathing spot, diffusion of responsibility most likely decreased, as there were fewer and fewer people present who could share the responsibility of taking an initiative between them. Furthermore, the reasons for doubting one's own judgement that here was a human being in distress weakened when the number of other bystanders went down, and so the foundation for collective ignorance gradually diminished.

In previous chapters, the bystander effect has been used as an element in efforts to explain why people hesitate to intervene when they sense that a colleague is about to make or already has made a mistake. It can happen during an innovation process, where everybody can agree upon the importance of being able to fail fast, but still are mute about a growing concern that this might not be a good project plan or idea after all. It can also happen when safety is at stake, and many people know about a possible weakness in a procedure, of either a systemic or a personal kind. Research on the bystander effect makes it plausible that the higher 
number of people who know about the weakness, the less likely it is that anybody will take a step forward and identify it.

When it comes to bystander effects that inhibit helping behavior, it is really the home turf for knowledge about this phenomenon. As we have seen, it is well documented that the likelihood of receiving help in a critical situation tends to increase when the number of bystanders goes down (Darley \& Latané, 1968; Fischer, et al., 2011; Darley \& Latané, 1976). In organizational settings, there can be situations that are parallel to the one experienced by the young man stuck in the stream. Many can be witness to a colleague who is struggling at work, and each can interpret what they see in the light of the behavior of his or her fellow bystanders. With a high number of bystanders often comes an illusion of being only minimally responsible for taking an initiative to help, and a sense that the situation might not be as serious as initially thought, since everybody else is behaving as if everything is fine.

In the current context, it is noteworthy that the bystander effect apparently can be reversed by means of cues that raise public self-awareness in public settings. With the introduction of nametags and cameras, participants in bystander experiments have been more helpful when other people are present than when they are alone, indicating that they are guided by concerns about the impression they make on others (van Bommel, van Prooijen, Elffers, \& van Lange, 2012, 2014). Reputation concerns and impression management lead to helping behavior. An unmonitored crowd offers anonymity and an opportunity to remain passive without fear of making a bad impression. In an organizational setting, this indicates that nametags and other ways of making bystanders identifiable can enhance the probability that somebody will take helping initiatives even when they are one of many. The presence of cameras is ethically problematic due to privacy issues, but the knowledge that the introduction of reputational concerns can reverse the bystander effect is nevertheless useful for efforts to raise help levels in response to fallibility at work. A person in need of help can also neutralize the bystander effect by pointing to one person in the crowd and ask him or her for assistance, instead of appealing in the general direction of all those present. That move can effectively puncture both diffusion of responsibility and collective ignorance, since it 
places one person in the spotlight and makes it clear that there is indeed a need for help.

Even the concept of confirmation fallacy can offer some explanation of both why a person in distress remains silent about his or her need for help, and why witnesses remain passive. Going back to the example from the river, the man stuck in the stream may have had an image of himself as a strong, muscular, mobile, and independent swimmer, who would never need help to get onto the shore after a dip in the river. The initial belief that he was capable to manage on his own may have remained with him, even after it was becoming obvious that it was false. Bystanders who took one look at him out in the river would also get a first impression of seeing an athletic person who appeared truly capable of taking care of himself. That assumption could survive the emergence of stark evidence to the contrary. In work settings, confirmation fallacy can also lead to initiatives to help colleagues who seem to need it, but in fact do not. The two alternatives to be conscious of, then, is that:

- A colleague who appears to be sufficiently competent and in control may actually be in trouble and need help.

- A colleague who appears to be in trouble and need help may actually be sufficiently competent and in control.

Research on confirmation fallacy suggests that we are slow to register changes in people's personal capabilities. Once we have supplied others with individual labels about what kind of people they are, we tend to be blind to obvious signs of negative or positive developments. It takes initiative to clarify whether first impressions are correct, and a colleague actually needs help, or not. That is what happened in the river episode, when a person on the shore finally took an initiative to inquire whether the man out in the strong current whether he needed help.

The most striking aspect of the incident in the river is the fact that the man in trouble did not ask for help himself, and had to be saved by another person's intervention. An appeal to a possible fixed self-image of being an independent and capable person cannot really function as the sole explanation. In the next section, attention turns to theories about how perceptions of social cost can inhibit people from seeking help. The 
act of asking others for help at work can be experienced as an admittance of defeat, of not being properly qualified for the job. Research on the real and apparent social costs of seeking help can clarify the extent to which a person is likely to be seen as less competent if he or she takes the step to ask for assistance at work.

\section{Perceived Social Costs of Seeking Help}

Reluctance to seek help in professional settings can create unacceptable risk and negative outcomes at work, since the solitary efforts of people who want to manage on their own can be inadequate in dealing with complex challenges. In the following, the point is illustrated through two narratives involving newcomers in healthcare who want to impress colleagues by demonstrating an ability to fix a problem without support from seniors. The first stems from an interview with doctor student Arne (not his real name), while the second is a fictitious account of what can happen when an inexperienced doctor attempts to be independent and autonomous in dealing with patient complications.

I had a summer job at a mental hospital, and was eager to do a good job and impress the staff there. I thought it would give me exciting and relevant experience, a chance to get good references, and maybe weekend jobs for later in my studies. Looking back, I got a bit overexcited in some situations. I was very active and engaged in meetings with patients who were suffering from psychosis, and tried to talk and reason with them, when what they really needed was rest. My behavior was quite intuitive, and I could have asked colleagues for help, and whether I was doing the right thing. (Arne, 2016)

This doctor student shows the same hesitancy as the man in the waterfall to admit to himself that he cannot deal with the situation alone, and needs help. Both appear to have a need to demonstrate independence and individual strength.

In one situation, I tried to convince a manic patient to reveal where she had hidden an ointment. Patients were not allowed to have medicine in 
their room, and this patient refused to hand over this ointment. A doctor and a nurse were present, and I got a chance to show them my capabilities. What I realized later, was that if the patient would not immediately reveal the hiding place, she was too ill to be a patient at this unit. I should have calmly asked for the ointment, and if she refused, that would mean she should have a transfer to another hospital. The patient was quarrelsome, but not violent. I employed all of my skills of conviction, and we had a fierce exchange of words about the hiding place for the ointment. In the end, I won through and the patient handed over the medicine. I asked for feedback from the colleagues who had been present. The nurse claimed that I had been too active in the situation, and should have simply asked for the ointment, and left the room if the patient refused. The doctor said that I have handled the situation quite well. Later I heard that the nurse that gone to the unit leader and complained about my behavior, saying that I was not competent enough to be left alone with patients. I went into this job too eager to make a positive impression and should have been more ready to seek help from colleagues and become involved in the teamwork of the place. (Arne, 2016)

When an organization hires students and other inexperienced people, there is a need to clarify expectations and ground rules. What are the normal ways of interacting in this place? How do you balance collaboration and individual work? When is it acceptable to ask for assistance, and who are available to help? It is not uncommon for a young person to enter an organization with the mindset exemplified by the doctor student above, eager to impress colleagues and demonstrate competence, autonomy, and independence. If an organization wants to keep such solo initiatives at bay, it needs to communicate it in advance, and be clear about what is the normal and expected ways of working together.

In healthcare, transparency about the expected balance between individual and collective efforts is particularly important. Newcomers can have an understandable need to show colleagues that they are trustworthy and competent, but may end up causing harm in the process. We can imagine the following scenario: A young doctor is present one afternoon when a child patient arrives at the unit. This girl is scheduled for an operation the next day. When the doctor on duty is about to leave the unit for 
the evening, he asks the young doctor if there is anything he should know about before he goes home. The young doctor now has the opportunity to describe the condition of the child patient, but decides not to do so. $\mathrm{He}$ wants to cope with the situation on his own, without support from senior colleagues. During the night, a complication occurs with the patient, and the young doctor can again choose to consult a senior doctor, but decides not to do so, thinking that he can and should handle the situation by himself. The patient is sleeping, and the young doctor believes that the complication can be dealt with when she wakes up in the morning. The patient dies, and would most likely have survived if she had received proper, routine treatment during the night.

When a hospital faces a situation of this kind, it is a test of its ability to perform an autopsy without blame (Collins, 2001), or a calm and clearheaded analysis of the chain of events where the main attention is on causes, rather than blame. It appears that the young doctor has made passive mistakes in (i) not consulting the senior doctor before he went off duty, and (ii) not calling for help when the complication happened during the night. From one perspective, these are personal mistakes for which he is accountable, while from another perspective, they are systemic mistakes. A verdict depends on whether the hospital has clarified expectations about doing things together rather than one by one. Both the real and fictitious examples of junior doctors who want to impress have a past, present, and future dimension, with corresponding questions (Table 1).

It may be that the principle of seeking help when you are in doubt or at the limits of your own capabilities seems so obvious that it should

Table 1 Time frame for help seeking

\begin{tabular}{lcl}
\hline Before & Critical quality moment & After \\
\hline $\begin{array}{l}\text { Did the organization } \\
\text { properly clarify for the }\end{array}$ & Should the junior be able & Will the student and \\
junior the normality & should seek help? & and improve practices \\
and expectation of & Should senior person- & of help seeking from \\
seeking help? & nel be more active in & the event? What are \\
& inquiring about the & the consequences for \\
& situation? & individuals and the \\
& & organization? \\
\hline
\end{tabular}


not be necessary to say it. However, patient safety in hospitals hinges on a deep, shared an understanding of this principle, and in meetings with inexperienced professionals, it seems reasonable to err on the side of over-communication rather than risk that they do not grasp the importance of seeking help when in doubt. Also, in the aftermath of critical event, it is possible to look at present routines and practices in order to consider improvements.

A person that refrains from seeking help from colleagues or others, even when he or she clearly needs it, is likely to perceive that the act of asking for assistance has some kind of social cost that they are unwilling to pay. Lee $(1999,2002)$ has proposed that there are three specific categories of social cost associates with seeking help. First, by asking for help one acknowledges incompetence and one's own inability to solve problems and find solutions by oneself. Second, a person seeking help acknowledges inferiority to other people in terms of knowledge, skills, and resources. Third, help seekers acknowledge their dependence on other people, and admit that they cannot complete a particular task along, but only through the efforts and contributions of others (Lee, 2002, p. 18). All of these categories of social cost have links to self-esteem. Admitting more or less publicly that you are not sufficiently competent, inferior, and dependent upon other people's contributions can disrupt a person's feeling of self-efficacy and being able to take care of him or herself. What will other people think of me, now that they have seem how dependent I am of help? These social costs can serve to explain the tendency to refrain from seeking help.

The doctor student's reluctance to seek help can be understood in the light of these theoretical propositions. He most likely wanted to avoid social costs in all three dimensions. First, he did not want to acknowledge incompetence, but instead had the ambition to make a good impression on colleagues and leaders at the mental hospital. Second, being a student he was already in some sense inferior to the other people in the workplace, and would not want to have the perceived gap in knowledge, skills, and resources widened even further by asking for help. Third, he acknowledges that he came into the organization with a plan to be perceived as an independent and autonomous person, someone who would deserve excellent references and offers of further 
assignments in the hospital. Asking for help would be detrimental to this plan. Only after feedback from the leader at the unit did he realize that the normal and expected behavior from newcomers was to seek assistance and be open about one's own shortcomings. Opportunities for further work at the hospital would have been greater if he had actively sought help from more experienced and competent colleagues.

In the fictitious case of the doctor who refrained from asking more experienced colleagues for help, we can imagine a similar set of reasons why he might have wanted to sort out complications with the patient on his own. He, too, is in a position where he wants to make a good impression and demonstrate that he can cope with complex cases on his own. All three dimensions of social cost are relevant to understand why someone in his position may avoid seeking help, even when the life of a child patient is at stake.

Gender differences can affect the threshold for seeking help. In a study conducted at a hospital, Lee (2002) followed the introduction of a new medication-ordering system, introduced in place of a system based on hand-written paper forms, and looked at how often people sought help from various sources when they encountered problems with the new system. She found that women were significantly more likely than men to seek help in such situations. That even held when comparing male and female doctors. Lee interprets these findings to mean that being competent, superior, and independent may be more important to male self-esteem than to female self-esteem. Gilligan (1982) proposed that women are socialized to value relational closeness and interdependence, while men to a stronger degree value independence and being able to look after oneself. There appears to be a gender difference when it comes to help seeking, and it can be important to acknowledge that, regardless of whether we consider that the causes are biological or social.

Another interesting finding in Lee's study is that tasks central to an organization's core competence, the ones that directly influence the organization's strategic advantage and competitiveness, are precisely the tasks for which the organizational members perceive the social cost of seeking help to be the highest. It appears to be harder and more socially costly, then, to seek help to perform tasks that people in the organization 
are supposed to be particularly good at. Lee (2002, p. 31) claims that acceptance of fallibility can be a key to improve the situation:

This suggests that managers should pay particular attention to increasing help seeking in the organization's area of core competence, for example by decreasing social costs through increasing interdependence between employees, by encouraging employees to try risky experiments that may fail, or by establishing norms that making mistakes is acceptable.

At hospitals, one can thus attempt to decrease the social cost of seeking help, by encouraging a teamwork mentality. The doctor student interviewed about his summer job experience at a mental hospital indicated that he was slow to understand the team dimension, and only gradually understood that it was normal to seek help from other team members. In other organizations, the issue can be to find ways to introduce risky activities, much in the same manner as described in chapter three regarding Søbakken nursing home. What constitutes a reasonable tolerance for risk and harm will always depend on the local circumstances, but a common feature is likely to be that one finds a balance between active and passive mistakes, or between prescriptive and proscriptive dimensions of morality.

Another finding from research in this field is that the social cost of seeking help is lower than common perceptions take it to be (Brooks, Gino, \& Schweitzer, 2015). The act of contacting another person to ask for help might even have a social gain rather than a cost. The study focused on the specific help seeking activity that consists in asking others for advice. Conventional wisdom and lay beliefs (as documented in two pilot studies for the main study) tend to be that asking for advice decreases perceptions of competence, but the results of the study indicate to the contrary that people tend to interpret acts of seeking advice as signs of high competence. The effect depends on the perceived complexity of the task: "When the task is difficult, asking for advice causes advice seekers to appear more competent than when they do when the task is not difficult; when the task is easy, asking for advice confers no benefit" (Brooks, et al., 2015, p. 547). It also makes a positive difference that the request for an advice is directed to the person who is going to 
assess the competence of the advice seeker. The dominant assumption appears to be that smart people ask for advice.

Perceptions of social cost can explain why people hesitate to seek help even in critical situations where their own capabilities are stretched. As we have seen in this section, emerging research provides us with reasons to reconsider establishes assumptions about the effect of help seeking on the perception of competence. Seeking help appears to have the potential to enhance social status, rather than diminish it. Knowledge in this field has the potential to change the way people think about fallibility and interdependence of work efforts, with a shift in focus from individualism towards teamwork and collective capabilities. It is likely to take conscious and systematic effort to establish a more team-oriented approach that acknowledges the limitations of what even the besttrained professionals can do on their own. Organizations can still expect that exceptionally gifted newcomers, with top results from top schools, will want to demonstrate their independence by managing on their own and not seeking help. Their leaders have an important task in communicating that it is perfectly normal and even required to ask for help and involve other team members in situations where they experience doubt and uncertainty.

\section{Systems of Holding Back}

When a person faces difficulties at work, help can be just around the corner, in the shape of a competent and experienced colleague who knows how to handle situations of this kind. All it takes is to get up from the chair and walk over to the colleague to ask for help. As we have seen in the previous sections, people tend to hesitate to do so in many contexts, and research on the psychological phenomena of the bystander effect and confirmation fallacy, as well as on the perceived social costs of seeking help provide input to understand and overcome the tendency to refrain from taking such initiatives. This section will consider another theoretical approach that also has the potential to explain the phenomena of not seeking or offering help. One thing is that the person who needs help at work remains at his or her desk 
instead of seeking help. Another is that the competent colleague may sense that a minor intervention can make a huge positive difference to the less experienced colleague, but still not make a move to offer or provide it. The ground cause for passivity in both cases may be what has been called systems of holding back (Hämäläinen $\&$ Saarinen, 2007).

A system of holding back is in place in a dyadic setting when person $A$ and person B are both thinking along the lines of "I will not contribute to an improvement in this relation, because the other person is not willing to contribute". Both A and B would appreciate and benefit from an improvement, but each of them mistakenly assumes that the other person is not interested or would not make an effort. The result is that nothing happens. There is no movement in the direction of changing the relation for the better, since none of the people involved is willing to take the first step. The situation resembles that discussed in the previous chapter, the wait-and-see attitude (Dutton, 2003) that can prevent colleagues from speaking openly about failures and mistakes. The shared assumption there can be that "I will not be vulnerable and talk about my mistakes, because he/she is not going to be vulnerable and talk about his/her mistakes". In professional settings, there can actually be a mismatch in people's readiness to be open about failure, as doctor Bjørnbeth experienced with his first, failed attempt to establish a routine of talking about mistakes. He met genuine resistance to the initiative to establish a climate for sharing professional experiences of not getting things right (Bjørnbeth, 2017). In other setting, there can be systems of holding back, where the people involved actually have a common wish to overcome muteness about failure, but each mistakenly assumes that they are alone in wishing for it.

The researchers who have identified systems of holding back as a feature of human behavior believe that it takes systematic effort to overcome it. In a work environment where people are holding back, the negative spirals can grow stronger:

The concept (of holding back) refers to mutually aggregating spirals which lead people to hold back contributions they could make because others hold back contributions they could make. We believe such systems are fundamental to human interaction - indeed, our conviction is that 
human interaction has a tendency to slide into systems of holding back unless conscious effort is launched to counter this tendency. A negative dance of holding back will prevail unless it is countered time and again. (Hämäläinen \& Saarinen, 2007, p. 26)

Efforts to disrupt systems of holding back can be Socratic in nature, and consist in raising questions about current practices. The Socratic motto "know yourself" can be interpreted as a reminder of the fact that we are relational beings. Knowing yourself is in this sense to become aware of the social systems you are a part of, and the extent to which you rely on contributions from others, and others rely on contributions from you. When you discern and contest systems of holding back, it can push individuals and groups in the direction of more constructive collaboration.

The philosopher David Hume has provided a vivid example of how two people can suffer from not overcoming initial reluctance to assist each other. One farmer notices that his neighbor needs help with his crop today, but refrains from helping because he does not expect the neighbor to assist him later when his crop is ripe:

Your corn is ripe to-day; mine will be so to-morrow.'Tis profitable for us both, that I shou'd labour with you to-day, and that you shou'd aid me to-morrow. I have no kindness for you, and know you have as little for me. I will not, therefore, take any pains upon your account; and should I labour with you upon my own account, in expectation of a return, I know I shou'd be disappointed, and that I shou'd in vain depend upon your gratitude. Here then I leave you to labour alone: You treat me in the same manner. The seasons change; and both of us lose our harvests for want of mutual confidence and security. (Hume, 1975/1737, pp. 519-520)

One striking feature if this narrative is that each farmer appears to know about the other that there would be no return of services. Their assumptions about each other may actually be well justified and true, and so constitute knowledge. When there is a negative dance of holding back, there is at least movement, and the assumptions it is based on can be 
challenged. Hume's farmers appear to have stopped dancing, and ended up in a toxic deadlock.

In a system of holding back, the situation is initially one where farmer A thinks that "I will not offer to help him get the corn into the barn today, because he is not willing to help me tomorrow" and farmer B thinks that "I will not seek help from him to get the corn into the barn today, because he will not trust me to help him tomorrow". Assumptions about what other people are willing to do may be false. The more cemented relation that Hume describes may be what lies ahead if the system of holding back continues without opposition. Initially, false assumptions about a lack of willingness to help may gradually become true, as the relation deteriorates. We can distinguish between fluid systems of holding back, where it might not take much effort to expose false assumptions about the other's lack of readiness to help, and a fixed system of holding back, where it has actually become true that the two individuals are not willing to seek or provide help to each other. It is possible to imagine how Hume's farmers have been neighbors for a long time, and that there was potential for seeking, asking for, and providing help at the early stage. Thirty or so years later, the lack of initiative from any of them to cancel out the system of holding back has created a standstill where both are losers.

Time is also a feature in many instances of coping adequately with fallibility at work. If colleague A has spotted that B colleague has misunderstood a routine or adopted a bad habit, the longer A waits to tell $\mathrm{B}$, the more awkward the situation is likely to become. We can imagine that $\mathrm{B}$ has misunderstood a particular written form they are using at work, and fills it in wrongly every time. A or other colleagues have adopted a habit of fixing the mistakes B makes, but nobody has taken an initiative to show him how the form is supposed to be filled in. If A picks a moment two years after these practices have been established to explain to B how it is really done, there are two things he or she will have to convey to B: (i) You have misunderstood the form, and filled it in wrongly, and (ii) I have known for 2 years without interfering and telling you. The thought of how awkward it will be to explain (ii) can contribute to more holding back from $\mathrm{A}$ and other colleagues in 
relation to B. The system of holding back can develop from being fluid to being fixed, unless somebody steps forward to turn things around.

The concept of holding back can serve to explain a range of instances where colleagues struggle to cope with fallibility. As illustrated with examples from aviation and healthcare, there can be critical situations where a mistake will lead to a negative outcome, unless somebody steps forward and intervenes to stop the chain of events that has been set in motion. People may hold back contributions they could make, based on assumptions about the extent to which the potential benefactor would have contributed if the roles had been reversed:

- I am not going to make him aware of his mistake, because he would not have made me aware of my mistake.

- I am not going to assist him in this critical phase of the project, because he would not have done the same for me.

- I am going to let him suffer through this on his own, because he would have let me suffer through a similar event on my own.

A common challenge in overcoming these systemic stalemates is to move from a passive mode to an active mode. As noted in chapter five, it is useful to distinguish between active and passive mistakes, between the mistake of doing something you actually should not have done, and the mistake of refraining from doing something you actually should have done. An active mistake is often salient by nature and tends to bring unwanted attention to the decision-maker, while a passive mistake can take place unnoticed, outside the spotlight. This asymmetry means that it is easier to get away with a passive mistake, compared to an active one. It can also strengthen systems of holding back, since passivity towards a habit of not supporting colleagues does not have the kind of obvious and tangible consequences that an active mistake can have.

The topic of this chapter has been how helping behavior can counter the challenges that occur due to human fallibility. In organizations where it is normal to seek, offer, and provide help to colleagues, the imperfect nature of professional capabilities is less likely to lead to bad outcomes than in organizations where people are more restrictive in those areas. The first example under scrutiny was one from a non-professional 
setting, where an athletic person stuck in a river stream refrained from asking for help. Similar situations can occur in organizations, when a person who apparently is competent and in charge of the situation, may actually need help, but be reluctant to ask for it. Three kinds of explanations of why people are reluctant to both seek and offer help have been discussed. First, bystander effects and confirmation fallacies can lead to passivity, in that both the person in trouble and the people watching may mistakenly think that this person is capable of managing on his or her own. Second, research on the perceived social cost of seeking help explains why the threshold for doing so can be high. It also exposes the perception to be dubious, in that studies show that help-seekers are often seen as more competent than those who try to do things independently and on their own. Third, systems of holding back can stand in the way of people seeking and offering help, in that people assume the other would not seek or offer help under reversed circumstances. There can be fluid systems of holding back, which can be challenged and exposed to be based on false assumptions about the other's willingness to make a positive difference, and fixed systems that have been allowed to develop over time and are harder to overcome. Conscious efforts to counter and challenge systems of holding back now appear to be central to any attempt to lay the foundation for adequate coping with fallibility at work.

\section{References}

Anderson, S. E., \& Williams, L. J. (1996). Interpersonal, job, and individual factors related to helping processes at work. Journal of Applied Psychology, 81(3), 282-296.

Arne, S. (2016, 10th December). Interview with student Arne/Interviewer: Ø. Kvalnes.

Bjørnbeth, B. A. (2017, 18th January).I nterviewer: Ø. Kvalnes.

Brooks, A. W., Gino, F., \& Schweitzer, M. E. (2015). Smart people ask for (my) advice: Seeking advice boosts perceptions of competence. Management Science, 61(6), 1421-1435.

Collins, J. C. (2001). Good to great: Why some companies make the leap... and others don't. NewYork: Random House. 
Darley, J. M., \& Latané, B. (1968). Bystander intervention in emergencies: Diffusion of responsibility. Journal of Personality and Social Psychology, 8(4), 377-383.

Dutton, J. E. (2003). Energize your workplace: How to create and sustain highquality connections at work. NewYork: Wiley.

Fischer, P., Greitemeyer, T., Kastenmüller, A., Krueger, J. I., Vogrincic, C., Frey, D., et al. (2011). The bystander-effect: A meta-analytic review on bystander intervention in dangerous and non-dangerous emergencies. Psychological Bulletin, 137(4), 517-537.

Gilligan, C. (1982). In a different voice. Boston, MA: Harvard University Press. Grant, A. M. (2014). Give and take: Why helping others drives our success. London: Penguin Books.

Grant, A. M., \& Patil, S. V. (2012). Challenging the norm of self-interest: Minority influence and transitions to helping norms in work units. Academy of Management Review, 37(4), 547-568.

Hume, D. (1975/1737). A Treatise of Human Nature. In L. A. Selby-Bigge \& P. H. Nidditch (Eds.). Clarendon Press: Oxford.

Hämäläinen, R. P., \& Saarinen, E. (2007). Systems intelligent leadership systems intelligence in leadership and everyday life (pp. 3-38). Systems Analysis Laboratory, Helsinki University of Technology.

Kahn, W. A. (1998). Relational systems at work. In B. M. Staw \& L. L. Cummings (Eds.), Research in organizational behavior. Amsterdam: Elsevier Science.

Katz, D., \& Kahn, R. L. (1966). The social psychology of organizations B2-The social psychology of organizations. New York: Wiley.

Latané, B., \& Darley, J. M. (1976). Help in a crisis: Bystander response to an emergency. Morriston, NJ: General Learning Press.

Lee, F. (1999). Verbal strategies for seeking help in organizations. Journal of Applied Social Psychology, 29(7), 1472-1496.

Lee, F. (2002). The social costs of seeking help. The Journal of Applied Behavioral Science, 38(1), 17-35.

Organ, D. W., Podsakoff, P. M., \& MacKenzie, S. B. (2006). Organizational citizenship behavior: Its nature, antecedents, and consequences B2Organizational citizenship behavior: Its nature, antecedents, and consequences. Thousand Oaks, CA: Sage.

van Bommel, M., van Prooijen, J.-W., Elffers, H., \& van Lange, P. A. (2014). Intervene to be seen: The power of a camera in attenuating the bystander effect. Social Psychological and Personality Science, 5(4), 459-466. 
van Bommel, M., van Prooijen, J.-W., Elffers, H., \& Van Lange, P. A. M. (2012). Be aware to care: Public self-awareness leads to a reversal of the bystander effect. Journal of Experimental Social Psychology, 48(4), 926-930. Weick, K. E. (1979). The social psychology of organizing. Reading, MA: Addison-Wesley.

Open Access This chapter is licensed under the terms of the Creative Commons Attribution 4.0 International License (http://creativecommons. org/licenses/by/4.0/), which permits use, sharing, adaptation, distribution and reproduction in any medium or format, as long as you give appropriate credit to the original author(s) and the source, provide a link to the Creative Commons license and indicate if changes were made.

The images or other third party material in this chapter are included in the chapter's Creative Commons license, unless indicated otherwise in a credit line to the material. If material is not included in the chapter's Creative Commons license and your intended use is not permitted by statutory regulation or exceeds the permitted use, you will need to obtain permission directly from the copyright holder.

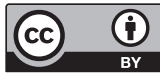

